\title{
Introduction: Presuppositions Philosophy, Linguistics and Psychology
}

\author{
Filippo Domaneschi
}

Published online: 21 January 2015

(C) Springer Science+Business Media Dordrecht 2015

\section{Mind the Gap (Between Semantics and Pragmatics)}

Presupposition has been a widely discussed topic in the philosophical and linguistic tradition since the beginning: Frege, in Über Sinn und Bedeutung (1892), claims that the use of a singular term presupposes the existence of the individual denoted. The Fregean example was that to give a truth value to the sentence

\section{(1) Kepler died in misery}

we need to take for granted the truth of the proposition

\section{(1a) Kepler existed}

Therefore, (1a) is a semantic presupposition of (1). Since the Fregean stance, analytic scholars have given the following definition: a sentence $p$ semantically presupposes a sentence $q$ if we need the truth of $q$ in order to treat $p$ as endowed with sense, that is, as either true or false. If the presupposition is lacking, then the sentence $p$ lacks a truth value (i.e. is neither true nor false). Russell, in On Denoting (1905), launched a strong criticism of the Fregean theory of semantic presupposition, contrasting the Fregean view with a new "theory of definite descriptions". From this perspective, every sentence is either truth or false, and the role of a proper name (or a description to which every proper name can be reduced, according to Russell) is to express an existence claim. This solution allows to give a truth value to sentences with non-denoting terms, like "The present king of France is bald", which should be translated as "There is an individual who is at present King of France and he is unique and he is bald"; formally:

F. Domaneschi $(\bowtie)$

Universität Konstanz, FB Sprachwissenschaft-H140,

78457 Konstanz, Germany

e-mail: Filippo.Domaneschi@uni-konstanz.de

\section{(2) $\exists x[\mathrm{~F}(x) \wedge \forall y[\mathrm{~F}(y) \rightarrow y=x] \wedge \mathrm{C}(x)]$}

In this case, given that there is no individual who is presently the King of France, the sentence is false.

It was only in the 50s that ordinary language philosophy developed a new concept of presupposition. Starting with Strawson (1950) and with Austin (1962), the concept of presupposition was no longer linked to necessary conditions for the evaluation of the truth of a sentence, but was a necessary condition for the felicity or appropriateness of a speech act. With Stalnaker (1973) analytic philosophy abandoned the notion of semantic presupposition to treat presupposition as a propositional attitude. The theory changed its focus from the semantic level of sentences to the pragmatic level of utterances, therefore including the 'cognitive context' of the speakers background of beliefs, assumptions, presumptions, etc. In Stalnaker's view the common ground of a conversation at a particular time is the set of propositions that participants in that conversation at that time mutually believe to be accepted as true and that, for that reason, they take for granted. Hence, in this perspective, a pragmatic presupposition is a prerequisite for appropriateness of assertions: an assertion of a sentence $p$ is appropriate only if the common ground includes the presupposition $q$ required by $p$, namely, $q$ is believed as accepted as true by the interlocutors (Stalnaker 2002).

In more recent times, several scholars have treated the problem of presuppositions within dynamic semantic theories, i.e. formal representations of language structure aimed at modelling the growth of information in the course of a discourse, like Update Semantics (Heim 1992) and Discourse Representation Theory (Kamp and Reyle 1993). The passage from the level of singular utterances to the wider level of the discourse structure has shown us that the distinction between semantic and pragmatic presuppositions, that once seemed 
like a neat division, is not so tidy after all. On the one hand, presuppositions are considered an essential prerequisite for understanding the content expressed by an utterance and for the coherence of the semantic relations between the sentences that constitute a discourse. In this respect, therefore, they play a purely semantic role. On the other hand, the process of presupposition accommodation is highly sensitive to contextual factors like, for example, speakers' willingness to maintain a cooperative attitude with their interlocutors. In this view, therefore, they can be considered a pragmatic phenomenon, related to contextual aspects.

\section{A Common Ground for Linguistics, Philosophy and Psychology}

Since the work of Grice (1989), linguists and philosophers of language identify three main levels of meaning characterizing an utterance in a context of use: the level of presuppositions, the level of what is explicitly said and the level of implicatures-e.g. the utterance 'I have given up smoking' presupposes that I used to smoke, explicitly says that I have given up smoking and it might implicate, depending on collateral assumptions, different contents, as, for instance, 'I have done something positive for my health' or 'You too ought to quit smoking!', and so on. Different theories of these three levels of meaning are currently under discussion: contextualism, minimalism, situationalism, relevance theory and relativism (see Preyer and Peter 2005; Penco and Domaneschi 2013). However, a widely shared assumption in the debate is that most of the information exchanged in verbal interactions is implicitly conveyed and presuppositions represent a large chunk of this implicit level of linguistic communication.

When dealing with presuppositions, many theoretical problems and contrasts have to be tackled. Specifically, there are three main open questions in the current linguistic and philosophical debate:

1. A first problem concerns what 'presupposing' means, i.e. what it is for a proposition to be taken for granted. The question at stake is to determine what are the mental states speakers have towards presuppositions; in particular, when new information is conveyed as presupposed and is accommodated within the common ground by the interlocutors.

2. A second major issue regards the role of presupposition triggers (i.e. all the lexical items and syntactic constructions that activate presuppositions). Besides a traditional taxonomy of presupposition triggers, there are now new attempts to better explain the mechanisms underlying the understanding of different categories of triggers and to provide a new classification.
3. Finally, a third central topic is the so called 'presupposition projection problem', namely, the problem of how complex sentences inherit the presuppositions of their components depending on the logical operator in use.

The primary purpose of this special issue of Topoi is to provide an updated survey of the different competing perspectives in philosophy of language and linguistics on the theme of presuppositions with respect to problems (1), (2) and (3). A further aim of the collection is to encourage new contributions in the area of experimental pragmatics (i.e. the development of pragmatics by experimental methods). The reason is that, in the contemporary debate on presuppositions, some very strong theoretical alternatives can be found but, while much experimental work has been developed to test the psychological plausibility of theories at the level of what is said and of what is implicated, an experimental research line on the pragmatics and semantics of presuppositions apparently is still underdeveloped-although recent works have provided significant contributions in this direction (see Schwarz 2014).

\section{The Papers Collected}

The present special issue faces many topics and theoretical perspectives surrounding the topic of presuppositions. The problem of characterizing what "presupposing" means is the common thread of the first series of papers contained in the anthology.

The first contribution in the collection is Barbara Abbott's paper "An information packaging approach to presuppositions and conventional implicatures". In this article, Abbott faces a core problem within the semantics and pragmatics literature: the distinction between presuppositions and conventional implicatures. Presuppositions and conventional implicatures share different properties like, first of all, "projectivity", i.e. the property of remaining constant in the scope of other operators. Taking into account information packaging, Abbott aims to clarify these different language usages by examining the property of projectivity together with two other properties shared by these projective contents: "strong contextual felicity" and "neutralizability".

According to the traditional account proposed by Peter Strawson, the falsity of a presupposition leads to a catastrophic consequence: a failure in the assertive enterprise. In "Presupposition Failure and the Assertive Enterprise" Anne Bezuidenhout proposes a discourse-based account of presuppositions based on the idea that presuppositions are 'assertorically inert', i.e. they are not part of the asserted content but rather background propositions. Bezuidenhout argues that presupposition failure can sometimes be non- 
catastrophic by examining cases in which, despite presupposition failure, the assertive enterprise works efficiently. In this view, she offers an account that illustrates the circumstances in which the falsity of a presupposition is catastrophic and those in which it is not.

The repair of a presupposition in case of failure takes place mainly by the 'accommodation' of the presupposition that is lacking. The problem of presupposition accommodation is the focus of Manuel Garcia Carpintero's paper "Accommodating Presuppositions". In this article, Carpintero elaborates an objection to Stalnaker's account of presuppositions, arguing that cases of informative presupposition represent a problematic aspect for his theory of pragmatic presuppositions and, more specifically, for the phenomenon of triggering of presuppositions. Carpintero defends here a more 'semantic' approach to the treatment of informative presupposition and supports the Lewisian notion of 'accommodation' describing it as a way in which interlocutors adjust themselves to one another when they are involved in a verbal interaction.

According to the traditional stance, a semantic presupposition represents a condition for the evaluation of a sentence as either true or false. Several authors have proposed semantic theories aimed at taking into account the phenomenon of presuppositions within multi-valued frameworks. Benjamin Spector in "Multivalent Semantics for Vagueness and Presupposition" proposes a strategy to model together presuppositions and vagueness by means of a trivalent semantics in which declarative sentences can not only receive the standard values true (1) and false (0), but also a third non-standard value "undefined" (\#). More specifically, Spector offers a multivalent account that contemporarily takes into account presuppositions and vagueness, captures their projection properties and distinguishes the different role played by these distinct phenomena in language.

The first experimental contribution collected in this special issue is the joint work of Cory Bill, Jacopo Romoli, Florian Schwarz and Stephen Crain: "Implicatures and Presuppositions in the Scope of Negation-Evidence from Acquisition". This article presents an experimental study on presuppositions and scalar implicatures in language acquisition. In contrast to the traditional view, recent works have supported the idea that the two kinds of inference are generated by the same mechanisms. The main result of the experiment discussed by the authors is that children and adults behave differently with respect to the two types of inferences. While this asymmetry is coherent with the traditional perspective, it represents a challenge for more recent accounts. In the conclusion, hence, the authors suggest a possible improvement of these recent approaches on the basis of the data collected and discuss the new experimental results in light of previous findings on processing presuppositions.
The combinatory restrictions known in linguistics as 'selection restrictions' are generally considered as a kind of linguistic structure. In "Selection restrictions as ultimate presuppositions of natural ontology" Michele Prandi argues that selection restrictions are criteria for conceptual consistency that form a layer of shared presuppositions that lie at the grounds of consistent thoughts and expressions and that belong to a natural ontology shared far beyond the boundaries of a given linguistic community.

The triggering problem is the second main topos of this special issue. Brian Leahy in "On Presuppositional Implicature" proposes an account of "presuppositional implicatures". According to Leahy, presuppositional implicatures should be classified as a special case of scalar implicatures: they arise when a speaker uses a presuppositionally weak alternative when a stronger one was available. More specifically, they occur when a presuppositionally weak alternative is felicitously used in a context that does not satisfy the presupposition of a presuppositionally stronger alternative, but where that stronger presupposition would have been accommodated.

The problem of the pragmatic mechanisms generating causal and temporal interpretations of "and" is one of the most discussed and problematic issues in the contemporary pragmatic debate. Joanna Blochowiak in "The presuppositional view on causal and temporal interpretations of 'and'", taking into account the Relevance Nomological Model, proposes an account based on presuppositional mechanisms developed within a broader and more comprehensive analysis aimed at explaining the various interpretations of 'and'-sentences and of other types of sentences involving similar interpretations.

The second relevant experimental contribution in the collection is "When "all the five circles" are four: new exercises in domain restriction". In this paper, Bart Geurts and Bob Van Tiel provide data from a series of experiments aimed at evaluating predictions about the problem of the determination of the domain of a quantifier. The quantificational domain, broadly speaking, is mainly determined on the basis of two factors: the context and the utterance through the presuppositions triggered within the sentence. Geurts and Van Tiel focus their attention on constructions like:

1. Q circles...

2. $\mathrm{Q}$ of these circles...

3. $\mathrm{Q}$ of these five circles...

... have the same colour as the square to which they are connected.

in which "the square to which..." is the critical presupposition trigger. Do the instances of these schemata give rise to the presupposition that every circle is connected to a square? The authors argue that, apart for some exceptions, 
these sentences should generally be accepted in contexts in which not all the circles are connected to a square. Moreover, they test the prediction that if the context is manipulated so as to make the connected circles more or less salient, then it should have an effect on statements with non-intersective quantifiers only.

A central aspect of the current debate on the presupposition projection, that is the third main issue of this collection, is the behaviour of presuppositions under the scope of operators. Presuppositions under negation, for instance, are likely to be projected but not mandatorily. Chris Cummins in "Using triggers without projecting presuppositions" underlines that this aspect leads to a difficulty for the hearer of presupposition-bearing utterances, in particular, when the speaker uses informative presuppositions. Cummins investigates the role played by the context in this phenomenon and, after having argued that the inferences that are drawn about the current discourse purpose can be relevant for the interpretation of potential presuppositions, discusses some implications of this aspect for experimental works on presupposition and projection.

In "Presuppositions as Anaphoric Duality Enablers" Christopher Gauker provides arguments against the account of presupposition projection based on Irene Heim's context-change semantics. Gauker claims that the presuppositions of a sentence can be identified only on the basis of prior utterances in the context of the conversation in which the sentence is uttered. By taking into account a three-valued semantics of assertibility and deniability in a context, Gauker claims that presuppositions can be explained as sentences which guarantee that the remaining assertibility and deniability conditions of the presupposition-bearing sentence are dual to one another.

The problem of presupposition projection is the core topic of the last paper of the collection. Amaia Garcia Odon in "Presupposition Projection and Conditionalization" aims to explain what is the main constrain in presupposition projection of composed sentences and supports the claim that the presuppositions that do not project are conditionalized, generating inferable conditional presuppositions.

\section{References}

Austin JL (1962) How to do things with words. Oxford University Press, Oxford

Frege G (1892) Über Sinn und Bedeutung. Zeitschrift für Philosophie und philosophische Kritik 100:25-50

Grice HP (1989) Studies in the way of words. Harvard University Press, Cambridge

Heim I (1992) Presupposition projection and the semantics of attitude verbs. J Semantics 9(3):183-221

Kamp H, Reyle U (1993) From discourse to logic. Kluwer, Dordrecht Penco C, Domaneschi F (eds) (2013) What is said and what is not. CSLI Publications, Stanford

Preyer G, Peter G (eds) (2005) Contextualism in philosophy. Knowledge, meaning and truth. Oxford University Press, Oxford

Russell B (1905) On denoting. Mind 14:479-493

Schwarz F (ed) (2014) Experimental perspectives on presuppositions. Springer, Berlin

Stalnaker R (1973) Presuppositions. J Philos Log 2:447-457

Stalnaker R (2002) Common ground. Linguist Philos 25(5-6): 701-721

Strawson PF (1950) On referring. Mind 59:320-344 